\title{
The effect of indexes, rankings and impact factors in accounting research and in accounting education in particular (Invited editorial)
}

Prof. Alan Sangster (a.j.a.sangster@btinternet.com)

\author{
Griffith University (Queensland, Australia)
}

Prof. Sangster is the editor of Accounting Education: An International Journal

http://dx.doi.org/10.12795/EDUCADE.2013.i04.01

This is very much a personal view, taken from a UK perspective, but others tell me that it resonates very much with what has happened elsewhere during the past decade or so. When I first became a higher education teacher of accounting in 1983, it was in a domestic science college in Scotland. I taught accounting to students who needed to use it in their careers, not as accountants but as hotel managers, cooks and chefs. The focus was upon the practicalities, the 'know how' of a technician, not the 'know why' of a professional accountant. In that job, there was no pressure to do research. But, I wanted to move to a university and that required that I could demonstrate that I could do research and that I had a higher degree than the bachelor's degree I held. Accordingly, I did a master of science degree part-time between 1984-6 and, in the course of doing it, I learnt for the first time what it meant to read, investigate, analyse, and write in an academic style. In 1987, I published my first research article and succeeded in moving to a university soon after. However, the only pressure I had upon me to do research up until 2004 related to seeking promotion or moving jobs. If I did not wish promotion or a change of university, there was no pressure upon me to publish, and many of my colleagues did just that: they did no research, but things were changing, slowly.

In the 1980s, a formal system of quasi-regular appraisals of staff research activity had begun in the UK. It took place every few years $(1986,1989,1992,1996,2001,2008)$ and some funding was set aside to reward those departments deemed to have done well. Universities and their departments gained a rating based on these exercises and this served as a driver of a gradual change in attitude towards those employed within them. Particularly in universities that prided themselves as centres of research, pressures to publish became more evident starting, in my case, to become noticeable when I moved jobs in 2004. However, for many years, this was something that motivated those interested in doing research rather than those who were not. Those that did not meet the research demands placed upon them could safely ignore the pressures and know that the worst that could happen was that they could be deemed to be 'non-research active' (which was true) and given more teaching than those who were 'research active'. 
For those of us in the accounting discipline, our colleagues in finance, and in the business schools, these research assessment exercises were qualitative whereby articles we had published were read by a panel of peers and judged on their individual merits. By 2008, this assessment was classified into 5 categories: world leading; internationally excellent; internationally original, significant, and rigorous; nationally original, significant, and rigorous; work of lower quality or not research. Some departments had created their own ranking lists so that they could guide their staff as to where to publish believing that doing so would ensure the papers submitted to the assessment process would be more likely to be assessed positively. Others, for the same reason, used a less formal system, such as suggesting that staff target journals of the American Accounting Association rather than domestic or European journals. But, the panel that reviewed the work submitted to it in 2008 continued to assess each paper they read on its merits. They did not, however, read all papers submitted to the exercise, there was no time to do so; and it is commonly believed that they used their own notion of the quality of the output among a number of heuristics in classifying the papers that were not read. Another heuristic used for this task was whether they were aware of the author's other work.

At this point, everything changed. The Association of Business Schools, an organisation formed by the Deans of UK Business Schools had adopted a journal rankings list first prepared by Bristol Business School in 2004 and the Deans as a group began to require its adoption as the guide to follow by the staff in their business schools. Almost overnight, the freedom to choose where to publish was removed. The choice of outlet had to be made from the journals in the discipline which were rated highly. No other outlets were acceptable. Books, which are not included in the journal rankings list, were considered a complete waste of time, even those which focused upon long-term external grant funded research projects and which, previously, would have been considered to be at least equivalent to refereed journal articles, if not the equivalent of at least two such articles. (Where I am now, in Australia, they are considered to be the equivalent of 5 published research papers.)

While this was not the case everywhere, it was where I was working at the time, and the impact of the decision was extreme: research projects in accounting education were abandoned; other research projects were abandoned which had been designed to develop non-researchers into research active faculty by giving them the experience of publishing in outlets in which it was easier to publish; research teams were disbanded; and, overall, what had been a blossoming centre of excellence in accounting education research created at the behest of management in 2007 was destroyed, virtually overnight, in mid-2009. Colleagues with $\mathrm{PhDs}$ in related areas were told that the publications they had spent two years securing were 'not good enough' and 'do better next time'. Six months earlier, they would have been congratulated and lauded in public. None of the staff that was being mentored to become research active ever published and most of those who were publishing left, including myself.

Now, four years on, things in the UK are still in a state of turmoil, with the ABS Journal Quality Guide becoming ever more a driver of what is acceptable. Targets were set generally for staff to achieve four 3-ranked publications if they were to be included in the research assessment exercise that concludes this year. Many could not achieve this: there are only so many outlets in accounting and finance which are ranked at that level. Now, talk is of the bar being raised to four 4-ranked publications for the next research assessment exercise planned for 2020. There is only one 4-ranked journal for accounting academics to target.

The psychological impact upon individuals of such requirements is not considered. I know many who are ill with depression and stress as a result of being rejected for 
inclusion in the current exercise. The impact upon areas of enquiry and scholarship, such as accounting education is not considered - there are no outlets ranked above 2 which normally consider accounting education papers, and those that do have started rejecting papers in this field because they are "accounting education" and enough has been published from that field of interest already. In many instances, citations and impact factors are considered vital, but many accounting journals and all journals specialising in accounting education are excluded from Thomson-Reuters ISI because, according to the gate keepers of the ISI, "the field is too small to have an impact". Academic papers in accounting education are as often about improving scholarship as they are about conducting research. The impact of such papers is never going to be reflected accurately in citation counts because it will be in the classroom, not in someone else's research paper. Yet, this fact is ignored in down-grading research in this field.

Accounting education research in the UK flourished from the early 1990s reaching a peak around 2010, when the impact of the managerial adoption of the ABS Journal Quality Guide began to take effect. From being the second largest source of papers published in this field, it has now slipped to relative insignificance: as editor of the only English-language specialist journal in accounting education located outside the USA (where there are five), for the past two years, less than $5 \%$ of submissions have been from the UK. To all intents and purposes, scholarship in accounting education in the UK is being terminated and is returning to how it was when I first began my career in the 1983. That is, those that care do what they can to make the learning experience more pedagogically meaningful for their students, experimenting, innovating, and intervening to improve the student experience, but the idea of publishing what they are doing is becoming less and less a by-product of the process, so others no longer hear of what is being done, of what works, and what does not. We are returning to our education silos.

This change is entirely due to ill-informed managerial adherence to a ranking of publication outlets which minimises credit for anyone who seeks to publish in a specialist outlet. The generalist outlets do not wish to consider specialist papers because there are specialist outlets. It is a viscous circle, and one that can only be broken by the specialist journals closing, something that cannot ever happen because such closure needs to be worldwide.

That is the situation in the UK. In Australia, it is no better. The latest draft issued last month of a new version of the Australian Business Deans Council journal ranking list, ranked only the American journal, Issues in Accounting Education at a level (A) which university managers consider to be of real merit. In order to be allowed to take a sabbatical, a colleague was told recently that three papers must be in review in journals at that level. How is someone who specialises in accounting education to do this? For those who undertake research in accounting history, as I do, it is even worse, no journal in that field is ranked above a B. Worse, individual funding for research is based upon publications and is awarded on the basis of the "quality" of published research. To obtain sufficient funds to travel to a conference anywhere, 'A-ranked' publications are needed. Working with teams of co-authors so as to publish in fields and outlets which are not your main area of expertise is not a way to overcome this, for the budget awarded is weighted by the number of authors. Any more than three authors and the amount awarded becomes insignificant.

In summation, all business school researchers are now being instructed to focus their efforts in a manner that restricts the academic freedom of the vast majority. It forces many to work in fields of which they know relatively little and lack the necessary expertise to make any real contribution. Fields that were previously considered acceptable, including accounting education, are now considered worthless, not 
because the scholarship quality has reduced, but because the specialist journals are not considered to be good enough by those who never undertake such research. It does not matter what the opinion is of those specialists for whom these are the only available outlet for their work. Editors of non-specialist journals are not willing to open their doors and publish papers in accounting education because specialist journals exist.

The result is that a branch of scholarship is being forced out of existence and many are the faculty who are suffering from being branded as second-rate, and it is not just those who research accounting education. It applies to many, even those who publish in more mainstream areas. There is a finite list of outlets and required "standards" are being raised, leaving less opportunity to publish and, because we can only submit to one outlet at a time and because the review process may keep a paper at one journal for as much as 3 years before it is rejected or accepted, publication is becoming more of akin to Russian roulette than a serious academic pursuit.

The only option we have is the long-worn one: fight back. We need to raise the standard of our journals as they are perceived by those who decide journal rankings. This requires that editors focus on articles that are more expansive in their selection of references, using sources that extend outside accounting education into mainstream discipline journals, not just in accounting or in education, but in any discipline the research of which may be relevant. Authors need to not only change their use of literature, they also need to focus more on developing articles around theory, something that is generally lacking in published output in this field. Editors also need to be stronger in requiring additional rounds of review and in using more than two reviewers. We are all going to have to re-group, start working in larger more broadly focused teams, and undertake research projects that will be more likely to raise the standards to new levels. Whether this means that the forms of research that we believe are most appropriate in this field must be set-aside remains to be seen, but it seems likely. Put these measures into practice, and there is hope that in the long-run, things may change. If they do, from our new position of increased strength, the sacrificed interests can be rekindled. 